\title{
Development and validation of the STEM Teaching Self-efficacy Scale (STSS) for early childhood teachers
}

\author{
Weipeng Yang ${ }^{1} \cdot$ Rongxiu $\mathrm{Wu}^{2,3} \cdot$ Juan $\mathrm{Li}^{4}$ \\ Accepted: 4 July 2021 / Published online: 9 July 2021 \\ (C) The Author(s), under exclusive licence to Springer Science+Business Media, LLC, part of Springer Nature 2021
}

\begin{abstract}
The preparation of STEM (science, technology, engineering, and mathematics) teachers for early childhood education (ECE) has clearly become an important issue in recent years. Teacher efficacy can lead to changes in professional beliefs toward and teaching practices in STEM. In this study, we developed the STEM Teaching Self-efficacy Scale (STSS) and validated it in a sample of 225 pre-service and 193 in-service early childhood teachers in Zhejiang, China. Results indicated preliminary evidence of reliability and validity of the two factors of STSS: Pedagogy Self-efficacy and Content Self-efficacy. Items were constructed based on literature and selected through factor analysis to cover the scope of self-efficacy on the behaviors of STEM teaching and ensure the content and construct validity of the scale. Scores on the STSS subscales were positively correlated with early childhood teachers' working status, age, occupational commitment, and interest in ECE, showing evidence of its criterion validity. The STSS provides a professionally and psychologically meaningful tool for evaluating early childhood teachers' efficacy beliefs about teaching STEM, which would help obtain evidence for the optimal design of STEM teacher training programs.
\end{abstract}

Keywords STEM education $\cdot$ Self-efficacy $\cdot$ Early childhood education $\cdot$ Pre-service and in-service teachers $\cdot$ Scale validation

\section{Introduction}

Self-efficacy is conceptualized as one's beliefs in being able to act on a certain situation to achieve specific goals (Bandura, 1977, 1997). Research demonstrates that teachers' selfefficacy significantly contributes to their persistence, commitment, job satisfaction and instructional quality (Holzberger et al., 2013; Klassen \& Chiu, 2011; Tschannen-Moran \& Hoy, 2001; Zakariya, 2020). The self-efficacy scale can be used to measure "generalized self-efficacy expectations dependent on past experiences and on tendencies to attribute success to skill as opposed to chance" (Sherer et al., 1982, p.

Juan Li

juanlihbu@sina.com

1 Department of Early Childhood Education, The Education University of Hong Kong, Hong Kong SAR, China

2 College of Education, University of Kentucky, Lexington, KY, USA

3 International Science \& Evidence Education (ISEE) Assessment, United Nations Educational, Scientific and Cultural Organization Mahatma Gandhi Institute of Education for Peace and Sustainable Development (UNESCO MGIEP), New Delhi, India

4 College of Education, Wenzhou University, Wenzhou, China
671), which is crucial to understanding and predicting individuals' behaviors (Bandura, 2006). In the disciplines of science, technology, engineering, and mathematics (STEM) which received increased attention in schools, self-efficacy is a strong indicator of teachers' confidence and skills to teach STEM (Geng et al., 2019; Gunning \& Mensah, 2011; JaipalJamani \& Angeli, 2017; Zakariya, 2020).

Recently, early childhood STEM education has become an important agenda for research and practice, as it can significantly predict children's increased school readiness, academic outcomes, problem-solving skills, scientific literacy, and employment in STEM fields in the long run (Chesloff, 2013; Early Childhood STEM Working Group, 2017; McClure et al., 2017). The implementation of high-quality STEM education in early childhood settings requires teachers' confidence and pedagogical beliefs in this regard (Chen et al., 2020), so as to meet the learning interests of young children who need to live and thrive in a digital and uncertain world. However, there is a lack of research on early childhood teachers' self-efficacy in STEM, leading to the relatively weak support for early childhood educators in teaching STEM. To address this knowledge gap, this study aims to develop and validate a STEM teaching self-efficacy scale for early childhood teachers. 


\section{Literature Review}

STEM as an acronym can be used differently in different research. In general, STEM education refers to an integrated and interdisciplinary approach to real-world problem solving in science, technology, engineering, and mathematics learning (Lantz, 2009; Wang et al., 2011). Sometimes STEM may intentionally refer to any of the four individual disciplines (Maher et al., 2013; National Academy of Engineering and National Research Council, 2014). In our literature review, we use both perspectives, as there is a scarcity of research on integrated STEM in early childhood education (ECE).

Prior research has explored early childhood teachers' beliefs toward integrating STEM in ECE. For instance, Tippett and Milford (2017) reported that early childhood educators considered STEM to be an important part of ECE. Park et al. (2017) further investigated early childhood teachers' beliefs about their readiness for teaching STEM and found that teachers' teaching experience and awareness about STEM would lead to different levels of perceived readiness for teaching STEM. In their scale used to evaluate teachers' beliefs in readiness for teaching STEM, items about teachers' self-efficacy in teaching STEM were included, such as "I know how to teach developmentally appropriate STEM subjects in my classroom." "I know the teaching strategies of STEM education." and "I have pedagogical knowledge about STEM teaching" (Park et al., 2017, p. 291). Simoncini and Lasen (2018) also examined Australian early childhood educators' beliefs toward STEM teaching and revealed that playbased and hands-on learning experiences were considered to be important for early childhood STEM education. Furthermore, Jamil et al. (2018) examined how early childhood educators perceived the STEAM (an extension of STEM to include "arts") approach to learning. They showed that teachers had a wide range of endorsement levels for early STEAM education. Their preliminary findings indicated that teachers' beliefs about STEAM education were related to their age, training experience, and teaching experience. This supports that early childhood teachers have varying levels of selfefficacy in facilitating early STEM learning. Although research has been conducted to examine early childhood teachers' beliefs or confidence in STEM teaching, there is a lack of instruments developed for measuring their selfefficacy in teaching STEM. Recently, Chen et al. (2020) developed a Teacher STEM Self-efficacy Scale in Taiwan for evaluating teachers' STEM competencies in the cognitive, affective, and skill aspects. However, the scale was only used in a sample of pre-service early childhood teachers.

In the field of mainstream education (i.e., elementary, middle and high schools), teacher efficacy in teaching STEMrelated subjects (e.g., mathematics and science) has been surveyed by the William and Ida Friday Institute for Educational Innovation (2012), with a scale of "Personal Teaching
Efficacy and Beliefs". Likewise, Lee et al. (2019) developed a scale for evaluating high school teachers' self-efficacy in STEM knowledge, which consisted of six factors: science, technology, engineering, mathematics, overall knowledge, and attitudes toward STEM education. However, the teacher efficacy and attitude scales used in these two studies are subject-based rather than integrated and cross-domain. It is important to promote the integrated approach to STEM education which encourages the use of knowledge across disciplines to solve real-world, complex problems among learners. According to Nadelson and Seifert (2017), it is crucial to engage students in integrated STEM learning opportunities in an era of synthesis, so as to enable them to connect and apply multiple STEM disciplines. The integration of STEM disciplines should start from teacher training and evaluation to ensure the authentic implementation of integrated STEM curriculum. To measure teachers' self-efficacy in teaching integrated STEM, Mobley (2015) has developed a scale of SelfEfficacy for Teaching Integrated STEM (SETIS), which consists of the social, personal, and material factors of self-efficacy. However, both scales were developed for mainstream education instead of ECE. To the best of our knowledge, there is a lack of measurement for evaluating early childhood teachers' self-efficacy in teaching STEM from an integrated perspective. Therefore, there is an urgent need to develop an integrated STEM teaching self-efficacy scale for early childhood teachers.

Although there are some studies investigating teachers' self-efficacy and beliefs in STEM domains (e.g., Chen et al., 2020; Çiftçi et al., 2020; Jamil et al., 2018; Park et al., 2017; Simoncini \& Lasen, 2018), none of them was conducted in mainland China. We thus know very little about Chinese early childhood teachers' self-efficacy in teaching STEM. To address this gap, this exploratory study developed and validated a scale for evaluating pre-service and in-service early childhood teachers' self-efficacy in teaching STEM in China.

\section{Early Childhood STEM Education in China}

China is running the world's largest ECE system, which provides services to 47 million children below 6 years in 2019 (Ministry of Education of China, 2020; Yang et al., 2020). In the national Guidelines for Kindergarten Education (Trial Version) (Ministry of Education of China, 2001), there are five suggested domains for ECE, including health, language, society, science (with mathematics included), and art (Yang, 2018). However, technology and engineering related learning is not included in this national ECE curriculum framework (Tao, 2019; Yang et al., 2020).

In practice, Chinese early childhood teachers tend to set goals for mathematics teaching, and would intentionally use age-specific curriculum resources ( $\mathrm{Li}$ et al., 2015). It is also found that mathematics teaching in Chinese early childhood 
classrooms usually follows the processes of teacher-led introduction of a topic, children's participation in topic-related games/ activities, and group sharing as a sum-up, which reflect a fusion of constructivism and instructivism (Huang et al., 2019; Li et al., 2019). In terms of early childhood science education, child-led inquiry has been promoted to replace teacher-directed instruction, with specific goals and educational suggestions given in the Guide for 3- to 6-Year-Old Children's Learning and Development (Gao \& Zhang, 2017; Ministry of Education of China, 2012). Chinese educational authorities have also advocated "Learning by Doing" as a notion for early childhood science education since 2001 (Gao \& Zhang, 2017). However, due to the regional differences and the inadequate access to teacher training, there exist individual differences in mathematics and science teaching among Chinese early childhood teachers. Moreover, teachers' self-efficacy in teaching STEM in an integrated approach remains understudied.

Accordingly, the present study investigated pre-service and in-service early childhood teachers' STEM teaching selfefficacy in China using a newly developed scale. This is important as individuals' self-efficacy is context and situation specific (Bandura, 1997). We firstly validated this scale using factor analysis, and then examined how the teacher-related factors would be associated with their STEM teaching selfefficacy to verify the criterion validity of the scale. The following questions guided this study:

(1) Is the STEM Teaching Self-efficacy Scale (STSS) valid and reliable for measuring early childhood teachers' selfefficacy in teaching STEM?

(2) How is the heterogeneity of STEM teaching self-efficacy as related to teacher-related factors, such as gender, age, grade of study, the working status (pre-service versus inservice), level of study (junior college versus bachelor), occupational commitment, professional interest, and working experience?

\section{Method}

\section{Participants}

A survey was administered to 418 pre-service and in-service early childhood teachers in Zhejiang Province, China after obtaining their informed consent. The pre-service teachers were enrolled in the Bachelor of Early Childhood Education program in a public university. In-service teachers were sampled from seven kindergartens in Zhejiang Province. Participants completed the survey about their self-efficacy in teaching STEM as well as the basic demographic items (398 female and 19 male teachers, one with unknown gender information but all the other items were completed) with ages ranging from 17 to 23 years old for the pre-service teachers $(N=225)$, and 20 to 48 years old for the in-service teachers $(N=193)$. The demographic characteristics of participants are shown in Table 1.

\section{Instruments}

The original STEM Teaching Self-efficacy Scale (STSS) was developed based on a thorough search of literature statements related to early childhood teachers' beliefs about STEM teaching. We adjusted the STEM Pedagogical Content Knowledge Scale (STEMPCK; Yıldırım \& Topalcengiz, 2019) to adapt to the early childhood context. The STSS initially included 40 items that were divided into five subcategories: Pedagogy, Science, Mathematics, Technology, and Engineering. Items were rated on a 5-point Likert scale ranging from 1 (not at

Table 1 Demographic characteristics of participants

\begin{tabular}{llll}
\hline & Pre-service & In-service & Total \\
\hline $\begin{array}{l}\text { Early childhood teachers } \\
\text { Gender }\end{array}$ & $225(53.8 \%)$ & $193(46.2 \%)$ & 418 \\
Male & 15 & 4 & $19(4.5 \%)$ \\
Female & 210 & 188 & $398(95.2 \%)$ \\
The degree the student is pursuing & & \\
Secondary School Diploma & NA & 1 & $1(0.2 \%)$ \\
Junior College Diploma & 95 & 82 & $177(42.3 \%)$ \\
Bachelor & 130 & 108 & $238(56.9 \%)$ \\
Master's & NA & 1 & $1(0.2 \%)$ \\
Others & NA & 1 & $1(0.2 \%)$ \\
Age & & & \\
17-23 & 224 & 47 & $271(65.5 \%)$ \\
$24-48$ & NA & 143 & $143(34.5 \%)$ \\
Grade of the Study & & & \\
Year 1 & 95 & 1 & $96(42.5 \%)$ \\
Year 3 & 46 & NA & $46(20.4 \%)$ \\
Graduate & 84 & NA & $84(37.2 \%)$
\end{tabular}

Do you wish to become a kindergarten teacher in the future

\begin{tabular}{lcll} 
Going & 121 & 119 & $240(60.1 \%)$ \\
Not sure/it depends & 90 & 59 & $149(37.9 \%)$ \\
Not going to & 4 & NA & $4(1 \%)$ \\
Are you interesting in the field of early & childhood education \\
Yes, interested & 119 & NA & $119(53.4 \%)$ \\
Not sure & 99 & NA & $99(44.4 \%)$ \\
No, not interested & 5 & NA & $5(2.2 \%)$ \\
How many years working in the kindergarten & \\
$1-10$ years & NA & 138 & $138(75.8 \%)$ \\
$11-20$ years & NA & 37 & $37(20.3 \%)$ \\
$21-30$ years & NA & 7 & $7(3.8 \%)$ \\
\hline
\end{tabular}

NA Not Available 
all like me) through 5 (very much like me). Items were reviewed by two experts in ECE back-to-back to ensure the clearness and practical relevance of statements before sending out for the survey.

Participants were also asked to complete a teacher survey in which they reported their demographic characteristics and professional background, which include their gender, age, grade of study, the working status (pre-service versus in-service), level of study (secondary school, junior college, bachelor, and more), occupational commitment, professional interest, and working experience (years of teaching).

\section{Statistical Analysis}

Data cleaning and descriptive analyses were performed in SPSS Version 25 (IBM Corp, 2017). We then conducted factor analysis and correlation analysis as follows:

Exploratory Factor Analysis. Due to the fact that STSS was initially self-developed based on the literature, initial dimensionality assessment was performed using an exploratory factor analysis (EFA) of the 40-item STSS with principal components analysis (PCA) as the method of factor extraction, to identify the underlying factor structure of the scale. The PCA, developed by Pearson (1901) and adapted for use in factor analysis by Hotelling (1933), summarizes the interrelationships among the original variables in terms of a smaller set of underlying dimensions. It is used when the researcher has no preexisting knowledge about the factors that may explain the interrelationships between a set of variables (Pett et al., 2003). The Kaiser-Meyer-Olkin test and Bartlett test of Sphericity were undertaken, both of which were used to establish the adequacy of the item correlation matrix upon which factor analysis was based. Criteria used for determining the number of factors to retain are parallel analysis, theoretical expectations, and interpretability. Factor loadings of 0.30 are considered as the minimum level for saliency, with loadings greater than 0.40 preferred (Hair et al., 2006). Items are considered as cross-loading if they load saliently on one factor and have a loading of above 0.30 on another factor. Poorly performing items based on a low loading on the primary factor or cross-loading were removed sequentially until all items fitted the criteria. EFA was performed in Mplus Version 8.1 (Muthén \& Muthén, 2018).

Correlation analysis. To examine criterion validity of the STSS, we performed Pearson correlation to examine the association between STSS scores and teacher-related variables (e.g., demographic characteristics) via SPSS Version 25 (IBM Corp, 2017).

\section{Results}

\section{Exploratory Factor Analysis}

The Kaiser-Meyer-Olkin coefficient for the original 40-item dataset was 0.97 and the Bartlett's Test of Sphericity was statistically significant $\left(\chi^{2}=12,081.10, \mathrm{df}=780, p<.01\right)$ indicating that properties of the correlation matrix justified factor analysis being carried out. With an oblique rotation, the factors were permitted to be correlated with one another.

Communality The extraction number for all the 40 items was higher than 0.60 , indicating that more than $60 \%$ of each variable's variance can be explained by the retained factors. From this aspect, these variables were well represented in the common factor space.

Parallel Analysis Parallel analysis indicated there were five sub-factors in total for the 40-item scale.

Pattern Matrix However, by inspection of the pattern matrix of the original 40 items, item 10, 18, 25, 27, 30, 31, 35, and 37 were all found to be cross-loaded and their secondary factor loadings were higher than 0.30. Item 17 and 26 were not found to be saliently loaded onto any factors. Therefore, these ten items were flagged as problematic ones in the initial inspection and were removed sequentially until all fitted the criteria.

Item 37 was deleted first since it had the highest crossloading value into another factor. Based on this rule, items were continued to be removed if cross-loading or low factor loadings for both primary and secondary factors existed. Therefore, item 10, 21, 35, 32, 16, 26, 17, 15, 33, 25, 27, $14,22,28$ and 34 were deleted sequentially because of its cross-loading or low factor loading. After these steps, item 13 was deleted since its communality was 0.487 , which was less than 0.50 .

Repeating the process, item 24, 29 and 30 were removed because of cross-loading and item 34 was deleted again because of its low communality $(<0.50)$.

We reran the analysis. The Kaiser-Meyer-Olkin coefficient for this dataset was 0.96 and the Bartlett's Test of Sphericity was statistically significant $\left(\chi^{2}=5501.24, \mathrm{df}=190, p<.01\right)$. Oblique factor rotation with the Direct Oblimin method, identified three latent factors. The three factors identified, comprising 20 of the original items, accounted for $66.90 \%$ of the total variance within the data. The results presented in Table 2 relate to factor analysis conducted using the 20 remaining items.

Lastly, we double checked the theoretical meaning for each item. Item 19 and item 23 were found to be repetitive in the meaning which was asked about science and mathematics; therefore, we decided to remove item 19 in the final scale. 
Table 2 Standardized factor loadings for items in the specified two-factor model of STSS

\section{9-item STSS}

Factor Loading

Factor $1 \quad$ Pedagogical Self-efficacy $(\omega=.94)$

Item 1 I can use more than one teaching strategy, method and technique in conducting a learning activity.

在开展教学活动时, 我善于使用多种教学策略、方法和技术。

Item 2 I can guide children's learning in every aspect

我能指导幼儿学习的各个方面。

Item 3 I can help children with their inquiry activities.

我可以帮助幼儿进行探究性活动。

Item $4 \quad$ I can use various approaches for evaluating children's learning.

我可以使用多种的幼儿学习评估方法。

Item 5 I can create an effective learning environment in classroom.

我可以在班级中创造一个有效的学习环境。

Item 6 I can communicate effectively with children.

我可以与幼儿进行有效的沟通。

Item 7 I can motivate students to participate in learning activities.

我可以让幼儿主动参与到教学活动当中。

Item 8 I can determine whether the children have achieved the learning goals.

我可以确定幼儿是否达到了目标。

Item 9 I can give children feedback on their learning.

我可以给幼儿有关学习的反馈。

Item 11 I can provide high-quality and efficient learning activities.

我可以提供高质量和有效的课程。

Item 12 I can conduct learning activities according to children's age and needs.

我可以根据幼儿的不同年龄特点开展教学活动。

Factor 2 Content Self-efficacy $(\omega=.90)$

Item 18 I can do advanced studies on science.

我可以对科学进行一些深入的了解与研究。

Item 20 I think that I am interested in conducting science learning activities.

我认为我对开展科学教学活动感兴趣。

Item 23 I encourage children to use math concepts.

我鼓励幼儿使用数学概念。

Item 31 I follow current developments in technology.

我关注技术的一些最新发展和趋势。

Item $36 \quad$ I think that I can help children in engineering education.

我认为我可以在工程教育方面帮到幼儿的学习。

Item 38 Doing activities related to engineering makes me feel good.

与工程相关的工作使我感觉很好。

Item 39 I think that engineering is fun.

我认为工程学很有趣。

Item 40 I can combine my teaching with engineering education.

我可以将自己的教学活动与工程教育结合起来。

For the final scale, The Kaiser-Meyer-Olkin coefficient for this dataset was 0.96 and the Bartlett's Test of Sphericity was statistically significant $\left(\chi^{2}=5157.54, \mathrm{df}=171, p<.01\right)$.

The communalities were in general higher than 0.50 .

Two factors were identified which comprised 19 of the original items. The first factor, which was labeled Pedagogy Self-efficacy, describes the teachers' self-efficacy in facilitating children's learning in early childhood settings. This factor accounted for $52.33 \%$ of the total variance and had an eigenvalue of 9.94. The second factor was labeled Content Self- efficacy to describe the teachers' self-efficacy in content knowledge related to the STEM domains. This factor accounted for $10.02 \%$ of the total variance and had an eigenvalue of 1.91 .

Internal Reliability We then calculated McDonald's omega $(\omega)$ (Hayes \& Coutts, 2020) to evaluate the internal reliability of the subscales. Internal consistencies were $\omega=0.94$ for the Pedagogy Self-efficacy subscale (items A1-A9, A11, A12), and $\omega=0.90$ for the left 8 items (Content Self-efficacy). 


\section{Criterion Validity}

The correlations obtained between the teacher-related variables and the two subscales of STSS are presented in Table 3. Participants with higher scores on the scale were more likely to believe in their capacity to facilitate children's learning in STEM. The Pedagogy Self-efficacy scores correlated positively with working status, age, and interest in ECE. This can be inferred that scores on Pedagogy Self-efficacy predicted working experience and professional interest. However, the Pedagogical Self-efficacy scores did not correlate with gender, grade of study, level of study (secondary school, junior college, bachelor, and more), occupational commitment, and years of teaching.

The results also provide some evidence of criterion validity for the subscale of Content Self-efficacy. The Content Selfefficacy scores were positively correlated with working status, age, occupational commitment, and interest in ECE. Hence, pre-service teachers who had commitment to being an early childhood teacher also had higher Content Self-efficacy. Gender, grade of study, level of study, and years of teaching did not correlate with the Content Self-efficacy scores.

\section{Discussion}

This study presented the development and model test of the STEM Teaching Self-efficacy Scale (STSS) for early childhood teachers. Its results thus provided preliminary evidence of reliability and validity of the two factors of STSS: Pedagogy Self-efficacy and Content Self-efficacy. Items were constructed based on literature and selected based on the evaluation of their contribution to psychologically important factors (through factor analysis) to cover the scope of selfefficacy on the behaviors of STEM teaching and ensure the content and construct validity of the scale.

The self-developed STSS has a similar purpose with the existing scale "Personal Teaching Efficacy and Beliefs" (The
William and Ida Friday Institute for Educational Innovation, 2012) which was designed to evaluate elementary teachers' self-efficacy and confidence for teaching specific STEMrelated subjects. However, the STSS is particularly designed for the population of early childhood teachers and can be used as a tool for monitoring the effects of early childhood teacher education and in-service training. Moreover, through an integrated, comprehensive assessment of teachers' self-efficacy in STEM teaching, the STSS moves beyond the traditional view of STEM as a collection of independent disciplines. In other words, the factor structure of STSS does not correspond to the four disciplines reflected in STEM. This is important as teachers' self-efficacy in teaching STEM subjects such as science and mathematics could be different from their selfefficacy in teaching integrated STEM. As noted by Bandura (1997), self-efficacy is situation-specific, so it may differ between the situations of subject-based and integrated STEM teaching experiences. This is also confirmed by Tao (2019) that although they have many years of teaching experience in traditional mathematics and science fields, Chinese kindergarten teachers have relatively low confidence in implementing integrated STEM education. More importantly, an integrated perspective for developing the STEM teaching self-efficacy assessment tool is in line with the international efforts in making STEM education more inclusive and interconnected across disciplines (Stremmel et al., 2015) to foster learners' twenty-first century skills (Hussin et al., 2019; Jamil et al., 2018; Johnson et al., 2015; Khalil \& Osman, 2017). Stohlmann et al. (2012) highlighted that integrated STEM education is a promising approach to more connected and relevant learning experiences for learners. It is especially urgent to investigate and enhance teachers' self-efficacy towards integrated STEM education when we consider the challenges facing teachers to connect across the STEM disciplines and provide STEM learning opportunities in authentic contexts (Kelley \& Knowles, 2016).

Other results of this study revealed the relationships between some teacher-related factors and scores on the STSS
Table 3 Pearson correlation of STSS scores and teacher-related variables $(N=418)$

\begin{tabular}{lllll}
\hline & Pedagogy $(r)$ & Content $(r)$ & STSS total $(r)$ & $N$ \\
\hline Working status (Pre-service or in-service) & $0.481^{* *}$ & $0.450^{* *}$ & $0.510^{* * *}$ & 418 \\
Gender & -0.017 & -0.008 & -0.014 & 417 \\
The degree the student is pursuing & 0.075 & 0.005 & 0.048 & 418 \\
Age & $0.397^{* *}$ & $0.341^{* *}$ & $0.407^{* *}$ & 414 \\
Grade of the Study & 0.116 & -0.010 & 0.071 & 226 \\
$\begin{array}{l}\text { Do you wish to become a kindergarten teacher } \\
\quad \text { in the future }\end{array}$ & 0.057 & $0.117^{*}$ & 0.091 & 393 \\
$\begin{array}{l}\text { Are you interesting in the field of early } \\
\text { childhood education }\end{array}$ & $0.167^{*}$ & $0.186^{* *}$ & $0.205^{* *}$ & 223 \\
How many years working in the kindergarten & 0.101 & 0.025 & 0.073 & 182 \\
\hline$* 0.05 ;{ }^{* *} p<0.01$ & & &
\end{tabular}


subscales. Scores on the STSS subscales were positively correlated with early childhood teachers' working status, age, occupational commitment, and interest in ECE. These results provided preliminary evidence of the criterion validity of STSS. It would be better if some other constructs such as teachers' STEM training backgrounds and their science instruction can be linked to the responses on the STSS. In terms of factors influencing teachers' self-efficacy in teaching STEM, we found that the more years the (student-)teachers had experienced in the field of ECE, they were more likely to have higher levels of self-efficacy in exploring STEM with young children. This is confirmed by Bandura's (1997) selfefficacy theory which argues that various factors such as individuals' mastery experience would play a significant role in their self-efficacy. For instance, as compared to pre-service teachers, in-service teachers may have more effective experiences in working with young children, which could have led to positive psychological change in terms of attempting something new (e.g., integrated STEM pedagogy) in early childhood settings. This finding is also consistent with Jamil et al.'s (2018) study which showed that early childhood teachers' age could predict their professional beliefs about integrated STEAM education, which adds "Arts" into STEM education. Meanwhile, high self-efficacy may lead to positive change of self-perception (Bandura, 1997; Kung, 2009). For example, early childhood teachers who have higher self-efficacy tend to have a higher self-perception of competence to work with young children, and thus produce higher levels of occupational commitment and professional interest in ECE. In contrast, individuals with low self-efficacy tend to have higher anxiety in related work and poor attitudes toward early STEM education. However, in the present study, evidence revealed that gender, grade of study, level of study, and years of teaching did not correlate with scores on the STSS subscales. This should be interpreted with caution due to a skewed distribution of participants in terms of gender, with only $4.5 \%$ of the participants being male. Also, the grade of study, level of study, and years of teaching were only applicable to part of the participants (either pre-service or in-service teachers), leading to the difficulty for interpreting the corresponding correlational findings.

\section{Limitations and Future Research}

Although this study has developed and validated STSS for measuring early childhood teachers' self-efficacy in teaching integrated STEM, it has a few limitations. First, due to a relatively small sample size, we only used EFA, internal consistency, and preliminary correlational evidence to support the reliability and validity of STSS. Some other techniques for validating the scale can be used in future research, including the confirmatory factor analysis (CFA) and concurrent validity. Second, the data source of this study was drawn from teacher-report questionnaires. Given that some research has found that there is a gap between teachers' self-perception of integrated STEM teaching and the authentic instructional practice (DeCoito \& Myszkal, 2018; Settlage et al., 2009), assessing teachers' pedagogical content knowledge and instructional practices is also of great importance for enhancing their STEM teaching experiences. Scenario-based measures can be used to supplement the reliance on teacher-report questionnaires (Gropen et al., 2017) for measuring early childhood teachers' beliefs and practices of STEM education. Indepth, qualitative studies such as teacher interviews and classroom observations can be conducted to understand how and why early childhood teachers may play out different levels of self-efficacy and competence in teaching STEM or implementing an integrated STEM curriculum. Third, we only validated the STSS in the Chinese cultural context, which may limit its validity in other countries. Therefore, it is necessary for future research to explore the validity of this scale in other cultural contexts, which will further support cross-cultural comparison. Last but not the least, we did not collect data for evaluating teachers' practices and child outcomes for this study. Future research is needed to further examine the relationships between early childhood teachers' STEM teaching self-efficacy, their instructional quality in STEM, and children's domain-specific (e.g., numeracy, science knowledge) and domain-general (e.g., approaches to learning, executive function) developmental outcomes.

\section{Conclusion}

Teacher efficacy can lead to changes in professional beliefs and even teaching practices (Hamre et al., 2012; Jamil et al., 2018; Tschannen-Moran \& Hoy, 2001). This study developed and validated a scale for evaluating early childhood teachers' self-efficacy in teaching STEM. It steps forward in the field through the employment of an integrated perspective for evaluating teachers' perceptions of early STEM education, explicitly deriving two important factors: Pedagogy Self-efficacy and Content Self-efficacy related to STEM teaching in early childhood settings. STSS thus provides a professionally and psychologically meaningful tool for evaluating early childhood teachers' beliefs about teaching STEM, which would help obtain evidence for the optimal design of STEM teacher training programs. The two factors of STSS also guide policymakers and teacher educators to focus on enhancing early childhood teachers' STEM pedagogical skills and content knowledge, which would allow them to cope with future challenges on the road to the provision of high-quality integrated STEM education for young children. 
Acknowledgements This work was supported by China's "Thirteenth Five-Year Plan" National Education Science Planning Project (BHA180143). In this difficult time, we would like to express our sincere appreciation to all the medical staff who have been fighting with COVID19 all around the world. Thanks also go to Dr. Bekir Yildırım for developing and sharing the STEMPCK scale.

Authors' Contributions Study design: WY; data collection: JL; data analysis: WY, RW; manuscript preparation: WY; and critical revisions to manuscript: WY, RW, JL.

Data Availability Not applicable.

Code Availability Not applicable.

\section{Declarations}

Ethical Approval All Procedures Performed in Studies Involving Human Participants Were in Accordance with the Ethical Standards of the Institutional and/or National Research Committee and with the 1964 Helsinki Declaration and its Later Amendments or Comparable Ethical Standards. Informed Consent Was Also Obtained from all Individual Participants Included in the Research. This Article Does Not Contain any Studies with Animals Performed by any of the Authors

Competing Interests On behalf of all authors, the corresponding author states that there is no conflict of interest.

\section{References}

Bandura, A. (1977). Self-efficacy: Toward a unifying theory of behavioral change. Psychological Review, 84(2), 191-215.

Bandura, A. (1997). Self-efficacy: The exercise of control. W. H. Freeman.

Bandura, A. (2006). Guide for constructing self-efficacy scales. In T. Urdan \& F. Pajares (Eds.), Self-efficacy beliefs of adolescents (pp. 307-337). Information Age Publishing.

Chen, Y. L., Huang, L. F., \& Wu, P. C. (2020). Preservice preschool teachers' self-efficacy in and need for STEM education professional development: STEM pedagogical belief as a mediator. Early Childhood Education Journal, 1-11.

Chesloff, J. D. (2013). STEM education must start in early childhood. Education Week, 32(23), 27-32.

Çiftçi, A., Topçu, M. S., \& Foulk, J. A. (2020). Pre-service early childhood teachers' views on STEM education and their STEM teaching practices. Research in Science \& Technological Education, 1-27.

DeCoito, I., \& Myszkal, P. (2018). Connecting science instruction and teachers' self-efficacy and beliefs in STEM education. Journal of Science Teacher Education, 29(6), 485-503.

Early Childhood STEM Working Group. (2017). Early STEM matters providing high-quality STEM experiences for all young learners: A policy report. UChicago STEM education; Erikson Institute.

Gao, X., \& Zhang, B. (2017). An overview of early childhood science education in China. In L. L. Liang, X. Liu, \& G. W. Fulmer (Eds.), Chinese science education in the 21st century: Policy, practice, and research (pp. 39-57). Springer.

Geng, J., Jong, M. S. Y., \& Chai, C. S. (2019). Hong Kong teachers' selfefficacy and concerns about STEM education. The Asia-Pacific Education Researcher, 28(1), 35-45.

Gropen, J., Kook, J. F., Hoisington, C., \& Clark-Chiarelli, N. (2017). Foundations of science literacy: Efficacy of a preschool professional development program in science on classroom instruction, teachers' pedagogical content knowledge, and children's observations and predictions. Early Education and Development, 28(5), 607-631.

Gunning, A. M., \& Mensah, F. M. (2011). Preservice elementary teachers' development of self-efficacy and confidence to teach science: A case study. Journal of Science Teacher Education, 22(2), 171-185.

Hair, J., Black, W., Babin, B., Anderson, R., Tatham, R. L., \& Black, R. (2006). Multivariate data analysis. Prentice Hall.

Hamre, B. K., Pianta, R. C., Burchinal, M., Field, S., LoCasale-Crouch, J., Downer, J. T., Howes, C., LaParo, K., \& Scott-Little, C. (2012). A course on effective teacher-child interactions: Effects on teacher beliefs, knowledge, and observed practice. American Educational Research Journal, 49(1), 88-123.

Hayes, A. F., \& Coutts, J. J. (2020). Use omega rather than Cronbach's alpha for estimating reliability. But.... Communication Methods and Measures, 14(1), 1-24.

Holzberger, D., Philipp, A., \& Kunter, M. (2013). How teachers' selfefficacy is related to instructional quality: A longitudinal analysis. Journal of Educational Psychology, 105(3), 774-786.

Hotelling, H. (1933). Analysis of a complex of statistical variables into principal components. Journal of Educational Psychology, 24(6), $417-441$.

Huang, R., Yang, W., \& Li, H. (2019). On the road to participatory pedagogy: A mixed-methods study of pedagogical interaction in Chinese kindergartens. Teaching and Teacher Education, 85, 8191.

Hussin, H., Jiea, P. Y., Rosly, R. N. R., \& Omar, S. R. (2019). Integrated 21 st century Science, Technology, Engineering, Mathematics (STEM) education through robotics project-based learning. Humanities \& Social Sciences Reviews, 7(2), 204-211.

IBM Corp. (2017). IBM SPSS Statistics for Windows, Version 25.0. IBM Corp.

Jaipal-Jamani, K., \& Angeli, C. (2017). Effect of robotics on elementary preservice teachers' self-efficacy, science learning, and computational thinking. Journal of Science Education and Technology, 26(2), 175-192.

Jamil, F. M., Linder, S. M., \& Stegelin, D. A. (2018). Early childhood teacher beliefs about STEAM education after a professional development conference. Early Childhood Education Journal, 46(4), 409-417.

Johnson, C. C., Peters-Burton, E. E., \& Moore, T. J. (Eds.). (2015). STEM road map: A framework for integrated STEM education. Routledge.

Kelley, T. R., \& Knowles, J. G. (2016). A conceptual framework for integrated STEM education. International Journal of STEM education, 3(1), 1-11.

Khalil, N., \& Osman, K. (2017). STEM-21CS module: Fostering 21st century skills through integrated STEM. K-12 STEM Education, 3(3), 225-233.

Klassen, R. M., \& Chiu, M. M. (2011). The occupational commitment and intention to quit of practicing and pre-service teachers: Influence of self-efficacy, job stress, and teaching context. Contemporary Educational Psychology, 36(2), 114-129.

Kung, H. Y. (2009). Perception or confidence? Self-concept, self-efficacy and achievement in mathematics: A longitudinal study. Policy Futures in Education, 7(4), 387-398.

Lantz, H. B. (2009). Science, technology, engineering and mathematics (STEM) education: What form? What function? CurrTech Integrations Report. http://www.currtechintegrations.com/pdf/ STEMEducationArticle.pdf

Lee, M. H., Hsu, C. Y., \& Chang, C. Y. (2019). Identifying Taiwanese teachers' perceived self-efficacy for science, technology, engineering, and mathematics (STEM) knowledge. The Asia-Pacific Education Researcher, 28(1), 15-23.

Li, X., Chi, L., DeBey, M., \& Baroody, A. J. (2015). A study of early childhood mathematics teaching in the United States and China. Early Education and Development, 26(3), 450-478. 
Li, X., McFadden, K., \& DeBey, M. (2019). Is it DAP? American preschool teachers' views on the developmental appropriateness of a preschool math lesson from China. Early Education and Development, 30(6), 765-787.

Maher, P. A., Bailey, J. M., Etheridge, D. A., \& Warby, D. B. (2013). Preservice teachers' beliefs and confidence after working with STEM faculty mentors: An exploratory study. Teacher Education and Practice, 26(2), 266-284.

McClure, E. R., Guernsey, L., Clements, D. H., Bales, S. N., Nichols, J., Kendall-Taylor, N., \& Levine, M. H. (2017). STEM starts early: Grounding science, technology, engineering, and math education in early childhood. Joan Ganz Cooney Center at Sesame Workshop.

Ministry of Education of China. (2001). Guidelines for Kindergarten Education (Trial Version). http://old.moe.gov.cn//publicfiles/ business/htmlfiles/moe/s7054/201403/xxgk_166067.html

Ministry of Education of China. (2012). Guide for 3- to 6-Year-Old Children's Learning and Development. http://www.moe.gov.cn/ srcsite/A06/s3327/201210/t20121009_143254.html

Ministry of Education of China. (2020). Statistical report of national education development in 2019: Number of students of formal education by type and level. http://www.moe.gov.cn/s78/A03/moe 560/jytjsj_2019/qg/202006/t20200611_464803.html

Mobley, M. C. (2015). Development of the SETIS instrument to measure teachers' self-efficacy to teach science in an integrated STEM framework. PhD Dissertation, University of Tennessee - Knoxville.

Muthén, L. K., \& Muthén, B. O. (2018). Mplus (version 8.1) [Computer program]. The Authors.

Nadelson, L. S., \& Seifert, A. L. (2017). Integrated STEM defined: Contexts, challenges, and the future. The Journal of Educational Research, 110(3), 221-223.

National Academy of Engineering and National Research Council. (2014). STEM integration in K-12 education: Status, prospects, and an agenda for research. The National Academies Press.

Park, M. H., Dimitrov, D. M., Patterson, L. G., \& Park, D. Y. (2017). Early childhood teachers' beliefs about readiness for teaching science, technology, engineering, and mathematics. Journal of Early Childhood Research, 15(3), 275-291.

Pearson, K. (1901). On lines and planes of closest fit to systems of points in space. The London, Edinburgh, and Dublin Philosophical Magazine and Journal of Science, 2(11), 559-572.

Pett, M. A., Lackey, N. R., \& Sullivan, J. J. (2003). Making sense of factor analysis: The use of factor analysis for instrument development in health care research. Sage.

Settlage, J., Southerland, S. A., Smith, L. K., \& Ceglie, R. (2009). Constructing a doubt-free teaching self: Self-efficacy, teacher identity, and science instruction within diverse settings. Journal of Research in Science Teaching, 46(1), 102-125.
Sherer, M., Maddux, J. E., Mercandante, B., Prentice-Dunn, S., Jacobs, B., \& Rogers, R. W. (1982). The self-efficacy scale: Construction and validation. Psychological Reports, 51(2), 663-671.

Simoncini, K., \& Lasen, M. (2018). Ideas about STEM among Australian early childhood professionals: How important is STEM in early childhood education? International Journal of Early Childhood, 50(3), 353-369.

Stohlmann, M., Moore, T. J., \& Roehrig, G. H. (2012). Considerations for teaching integrated STEM education. Journal of Pre-College Engineering Education Research (J-PEER), 2(1), Article 4.

Stremmel, A. J., Burns, J., Nganga, C., \& Bertolini, K. (2015). Countering the essentialized discourse of teacher education. Journal of Early Childhood Teacher Education, 36(2), 156-174.

Tao, Y. (2019). Kindergarten teachers' attitudes toward and confidence for integrated STEM education. Journal for STEM Education Research, 2(2), 154-171.

The William and Ida Friday Institute for Educational Innovation. (2012). Teacher efficacy and beliefs toward STEM survey. Author.

Tippett, C. D., \& Milford, T. M. (2017). Findings from a pre-kindergarten classroom: Making the case for STEM in early childhood education. International Journal of Science and Mathematics Education, 15(1), $67-86$.

Tschannen-Moran, M., \& Hoy, A. W. (2001). Teacher efficacy: Capturing an elusive construct. Teaching and Teacher Education, 17(7), 783-805.

Wang, H., Moore, T. J., Roehrig, G. H., \& Park, M. S. (2011). STEM integration: Teacher perceptions and practice. Journal of PreCollege Engineering Education Research, 1(2), Article 2. $10.5703 / 1288284314636$.

Yang, W. (2018). Early childhood curriculum as cultural practice: A comparative study of school-based curriculum development in Hong Kong and Shenzhen. PhD Thesis, The University of Hong Kong.

Yang, W., Xu, P., Liu, H., \& Li, H. (2020). Neoliberalism and sociocultural specificities: A discourse analysis of early childhood curriculum policies in Australia, China, New Zealand, and Singapore. Early Child Development and Care, 1-17.

Yıldırım, B., \& Topalcengiz, E. S. (2019). STEM pedagogical content knowledge scale (STEMPCK): A validity and reliability study. Journal of STEM Teacher Education, 53(2), 2.

Zakariya, Y. F. (2020). Effects of school climate and teacher self-efficacy on job satisfaction of mostly STEM teachers: A structural multigroup invariance approach. International Journal of STEM Education, 7(1), 1-12.

Publisher's Note Springer Nature remains neutral with regard to jurisdictional claims in published maps and institutional affiliations. 